\title{
Editorial
}

\section{The importance of the right to science during pandemics}

\author{
Natallia Sianko ${ }^{1}$, Albina Balidemaj Basha ${ }^{2}$, Mark Small ${ }^{1 *}$ \\ ${ }^{1}$ Clemson University, Clemson, South Carolina 29634, USA \\ 2 The American University in Kosovo, Rochester Institute of Technology, Germia district of Pristina, Kosovo
}

Few articles of the Universal Declaration of Human Rights (UDHR) have received less attention than the right to science. All signatory members agreed that the right of everyone to "share in scientific advancement and its benefits" [Article $27(1)$ ] is to be promoted and protected in every place around the globe (United Nations, 1948). The right to science is further secured in the International Covenant on Economic, Social and Cultural Rights (ICESCR). This not only reaffirms it as a basic human right, but also, upon coming into force in 1976, established the responsibility of governments to respect the right of everyone to "enjoy the benefits of scientific progress and its applications". States are required to conserve, develop and diffuse science, respect the freedom indispensable for scientific research, and encourage international contacts and cooperation in science [Article 15(1) (b)].

Of the 30 articles in the Universal Declaration of Human Rights, the right to science has perhaps the most complex history. Spanning more than seven decades, from its earliest expression in the UDHR in 1948 to a formal interpretation of the scope of its content by the UN Committee on Economic, Social and Cultural Rights (CESCR) in 2020, the right to science was deliberated during a formative time in which knowledge and application of scientific advances became critical to all forms of everyday life. Fortunately, one of the outcomes of this extensive deliberation and analysis of the right to science is a framework that can be used by governments and other stakeholders to address pressing societal challenges. As of 2019, the most pressing social challenge is the pandemic caused by a coronavirus, commonly referred to as COVID-19.

Within the proposed framework, the General Comment elaborates upon five elements that define the contours of the right to science, namely, availability, accessibility, acceptability, quality, and the protection of freedom of scientific research (CESCR, 2020, paras 16-20). Also within the framework, the General Comment lists four key measures that States must put in place to advance the right to participate in and enjoy the benefits of scientific progress (CESCR, 2020, paras 86-89). These include: (a) the establishment of a normative legal framework that protects against all forms of discrimination; (b) the development of a national plan to promote and disseminate scientific progress to all individuals, taking into account protections against misleading pseudoscience as well as ensuring ethical standards in science; (c) the identification of benchmarks to monitor the implementation and progress of the right to enjoy the benefits of scientific progress at the national level; and, (d) the establishment of judicial and administrative mechanisms that will allow victims of this right to access appropriate remedies.

As we write this editorial (December 2020), the spread of coronavirus and its consequences are at the forefront of global public concern. A universal human rights approach appears well-suited to address a universal health care problem. Using the right to science to frame a universal response to the pandemic is a unique opportunity to elevate the status of this right and provide concrete examples of how it should be applied. This is especially critical given that many elements remain unimplemented and the potential is not fully realized. The pandemic has given us a chance to take this right seriously and examine how a more fully realized implementation of the right to science would allow a better response for the next pandemic. Accordingly, some of the elements associated with the right are elaborated upon here.

\section{Availability}

During the early stages of the pandemic, the availability of scientific information related to the nature and extent of the virus infection was limited. In January of 2020, the World Health Organization (WHO) still had doubts about the origins of what would become the COVID-19 pandemic. Reported symptoms included a wave of pneumonia-like cases in Wuhan that could have stemmed from a new coronavirus. At this point, there were about 59 cases and travel precautions were already at the front of experts' concerns. The COVID-19 went on to be officially declared a pandemic in March of 2020, which resulted in countries closing borders and quarantining citizens. Arguing that no one is safe until everyone is safe, the WHO started urging countries and scientists to collaborate, in an attempt to bring the pandemic under control. The main aim was to create (alongside governments, the private sector scientists, foundations, and other partners) groundbreaking platforms to fast track the production of tests, treatments and vaccines.

\footnotetext{
* Corresponding author: Mark Small, Clemson University, Clemson, South Carolina 29634, USA; e-mail: MSMALL@clemson.edu http://doi.org/10.32725/kont.2021.012

Submitted: 2021-01-19 • Accepted: 2021-03-10 • Prepublished online: 2021-04-08 
Between March and October, the WHO alongside human rights chief and Director-General of science, issued a call for 'open science' labelling it as a "fundamental matter of human rights", and arguing for pioneering tools and findings to be available for those who need them most. A goal of 'open science' is to expedite scientific cooperation and the sharing of information for the benefit of science and society, creating better scientific knowledge, and distributing it to the broader population. Made possible with the widespread use of digital technology, an "open science" is fully consistent with ideals embodied in the right to science and well-suited to address concerns of pandemics.

\section{Accessibility}

As scientific knowledge of the virus increased, there were questions regarding who had access to scientific findings and when access to such knowledge would be become widely available. Ideally, rapid access to data and research results is made available so that meaningful action could slow the spread of the virus while appropriate preventive and treatment approaches were developed. To some extent this occurred during the pandemic, though there were obstacles, both old and new, that prevented quicker and more efficient access to scientific findings.

Older obstacles included the traditional time necessary to insure peer review of research, the time needed for revisions and publishing, the frequent necessity of having a paid subscription to the database containing the information, and the privacy, confidentiality, and proprietary issues that prevent access to original raw data. Newer obstacles that related specifically to the pandemic include the governmental suppression of information related to the pandemic, misinformation regarding the origin of the virus, and misinformation regarding the efficacy of various preventive and therapeutic measures. Indeed, the role of some country leaders in misleading their citizens as to the scientific consensus on the nature and extent of the virus's impact is directly opposite to the spirit and intent of the right to science.

A more fully implemented right to science would require strengthening national capacities for conserving, developing, and diffusing science; respecting academic freedom, enhancing public trust in science through education; and recognizing the benefits of international co-operation in the scientific field by sharing knowledge and acting with greater urgency on mattes of global concern. As noted in a recent review of articles on the right to science: "Access was the only theme that appeared universally. Articles discussed the importance of access to all parts of science, from the necessary education all the way to the data, knowledge, and applications that arise from scientific inquiry. Access interests range from those of the general public to those of researchers." (Porsdam Mann et al., 2018, p. 10821)

\section{Acceptability and quality}

Availability, which refers to States' obligation to "take steps for the conservation, the development and the diffusion of science"; and quality, which refers to States' obligation "to regulate scientific applications and ensure access to verifiable science" have proven problematic during the pandemic. As information about the pandemic became available, misinformation also became available. Acceptability to verifiable science was undermined by public pronouncements questioning the peer review process and promoting untested theories related to prevention and treatment. Scientific information became politicized, and official government pronouncements only served to confuse citizens. For example, in China, information regarding the extent of harm from the virus was initially sup- pressed. In the United States, the President's declarations often conflicted with those of the government agencies responsible for public health. With world interest in accurate and timely information, the disregard by States in diffusing science caused confusion for other State leaders. Consequently, many countries were late to prepare for the impact of COVID-19. For the next pandemic, a more fully implemented right to science will include safeguards against politicization, perhaps with the World Health Organization, Gates Foundation or some other trusted entity establishing early credibility.

Additionally, the right to science requires States to take steps, "to the maximum of their available resources, for the full realization of the right to participate in and to enjoy the benefits of scientific progress and its applications". Relevant to the current pandemic, plans currently are underway for widespread vaccination and the ultimate success of global vaccination efforts will depend on citizens' willingness to participate. With significant numbers of people who disagree with the use of a vaccine (known as anti-vaxxers), States will need to make concerted efforts to ensure that the benefits of scientific progress are universally applied. A fully implemented right to science will necessarily involve improved State efforts for citizens to be scientifically literate.

\section{Protection of freedom of scientific research}

As an indispensable element of the right to science, freedom of scientific research has perhaps the most direct implications for the current pandemic. Multidimensional by nature, freedom of research encompasses myriad aspects that, once acted upon either independently or together, hold the most promise not just to effectively meet the pressing challenges of ongoing disruptions caused by the pandemic but also to prevent them from causing more harm in the future. Some of the dimensions articulated in the General Comment include: protection of researchers from undue influence on their independent judgment; the possibility for researchers to set up autonomous research institutions and to define the aims and objectives of the research and the methods to be adopted; the freedom of researchers to freely and openly question the ethical value of certain projects and the right to withdraw from those projects if their conscience so dictates; the freedom of researchers to cooperate with other researchers, both nationally and internationally; and the sharing of scientific data and analysis with policymakers, and with the public wherever possible (CESCR, 2020, para 13).

\section{Recognizing the benefits of scientific collaboration}

A fully implemented right to science would multiply the benefits of collaboration. For example, consider the current competition to produce and distribute an effective vaccine. To be sure, the scientific enterprise is now global with fluid borders facilitating the exchange of ideas across disciplines and cultural contexts. Yet, the production of science is uneven, with scientists embedded in different socio-political contexts that have varying levels of financial and social support and varying levels of government commitment to collaboration. These differences can create substantial barriers to sharing contributions from different scientists united by a common goal of stopping a pandemic. Although some sharing has occurred, there is much room for improving scientific exchange. Imagine if all pandemic related information was free.

A more complete implementation of the right to science would go beyond governmental action. Indeed, all sectors of society including professional and business organizations, civil society groups and faith-based organizations are need- 
ed. Building on the momentum created by the adoption of the General Comment, some organizations have taken steps to improve the scientific landscape in the context of the pandemic. One such example is a recent initiative of the Treatment Action Group (TAG), an advocacy and community-based research and policy think tank dedicated to fighting for better treatment, prevention, a vaccine, and a cure for HIV, tuberculosis, and hepatitis $C$ virus. In their special edition of Tagline (organization's flagship publication) dedicated to the right to science, the authors reviewed the content of the General Comment while calling their members to join TAG in formulating answers to the following questions: Is there a difference between scientific knowledge and applications? Who can access these benefits? How should governments best promote science when nonstate actors carry out so much research? (Flick, 2020). Another example is the American Association for the Advancement of Science which has created a repository with public access to a variety of resources on the implications of human rights for tackling the pandemic and on the application of the pandemic responses to advance human rights (Science and Human Rights Coalition, (c) 2021).

\section{Summary}

There is increasing recognition of the importance of the right to science. For example, "in the U.S., as we enter the fiscal year 2021 appropriations season, there are clear opportunities to put the right to science into practice. Investments across the full spectrum of research and development - in the National Institutes of Health, the Center for Disease Control and Prevention, U.S. Agency for International Development, the Biomedical Advanced Research and Development Authority, and the Food and Drug Administration - are essential" (Lessem and Madoori, 2020). And in words of Erica Lessem and Suraj Madoori (2020) of the Treatment Action Group: "Whether fighting the oldest infectious disease known to humans, or this new pandemic, the right to science offers us an invaluable frame for our activism and for reframing government policy." This recognition is an important first step for States to commit more fully to their human rights obligations. Regarding the right to science, there are still benefits to be gained during this pandemic and lessons to be learned for the next one. Science never mattered more.

\section{References}

1. CESCR - UN Committee on Economic, Social and Cultural Rights (2020). General comment No. 25 on science and economic, social and cultural rights [article 15 (1) (b), (2), (3) and (4) of the International Covenant on Economic, Social and Cultural Rights], E/C.12/GC/25. [online] [cit. 2020-12-12]. Available from: https://undocs.org/E/C.12/GC/25

2. Flick M (2020). The right to science finally comes into sight. What the General Comment on the Right to Science means for health advocacy. Tagline 28(1). [online] [cit. 2020-1212]. Available from: https://www.treatmentactiongroup.org/ wp-content/uploads/2020/05/tagline_05_2020_rts_finally_ comes_into_sight.pdf

3. Lessem E, Madoori S (2020). Realizing the right to science. Tagline 28(1). [online] [cit. 2020-12-09]. Available from: https://www.treatmentactiongroup.org/wp-content/ uploads/2020/05/tagline_05_2020_intro_realizing_right_to_ science.pdf

4. Porsdam Mann S, Donders Y, Mitchell C, Bradley VJ, Chou F, Mann M, et al. (2018). Opinion: Advocating for science progress as a human right. Proc Natl Acad Sci USA 15(43): 10820-10823. DOI: $10.1073 /$ pnas.1816320115.

5. Science and Human Rights Coalition (@ 2021). Responding to COVID-19: Science and Human Rights. American Association for the Advancement of Science. [online] [cit. 2021-01-22]. Available from: https://www.aaas.org/programs/science-andhuman-rights-coalition/responding-covid-19-science-andhuman-rights?et_rid=206153956\&et_cid=3591808

6. United Nations (1948). Universal Declaration of Human Rights. New York: U.N. Department of Public Information. [online] [cit. 2020-12-02]. Available from: www.un.org/en/documents/udhr 